\title{
ENSEÑANZA DE LAS CIENCIAS \\ EXPERIMENTALES MEDIANTE ENFOQUE \\ INTERDISCIPLINARIO UTILIZANDO EL IMPACTO \\ AMBIENTAL GENERADO POR \\ LAS EMISIONES DE $\mathrm{CO}_{2}$
}

\section{Jairo Enrique Guerrero Santa fé* Luz Marina Cabrera Morillo**}

\begin{abstract}
Teaching Experimental Sciences by interdisciplinary approach using the environmental impact generated by natural and artificial emissions of $\mathrm{CO}_{2}$, will facilitate the interaction and relation of phenomena and problems of the environment whit class activities, through integrate concepts from which we can articulate concepts of discipline or concepts of and experiences of one discipline with other areas of knowledge, in such a way that we can study such situations with their impacts, proposing educational, technological and legal alternatives.
\end{abstract}

\section{RESUMEN}

La enseñanza de las ciencias experimentales con enfoque interdisciplinar, utilizando el impacto ambiental generado por las emisiones naturales y artificiales de $\mathrm{CO}_{2}$, facilitará la interacción de los fenómenos y problemas ambientales con las actividades del aula a través de conceptos integradores que permitan articular conceptos de una disciplina, o conceptos y experiencias de una disciplina con conceptos y experiencias de otras disciplinas o con otras áreas del conocimiento, facilitando el estudio de tales situaciones con sus impactos y propiciando alternativas de control desde lo educativo, tecnológico y legal.

\section{INTRODUCCION}

Las interacciones antropico-naturales han generado situaciones riesgosas con alto grado de impacto sobre la sostenibilidad del planeta. Para comprender el significado y la dimensión de tales relaciones, es posible utilizar en la enseñanza de las ciencias experimentales, el estudio del impacto ambiental producido por las emisiones de $\mathrm{CO}_{2}$.

\footnotetext{
${ }^{*}$ Profesor Titular Universidad Pedagógica Nacional.

Corporación Universitaria de Ciencias Aplicadas y Ambientales.
} 
La combustión de materiales orgánicos e inorgánicos con el propósito de obtener energía y otros subproductos como materia prima para diferentes procesos industriales, está acompañada de emisiones gaseosas, entre las cuales se destaca la emisión de $\mathrm{CO}_{2}$. Parte del dióxido de carbono producido, es absorbido por las plantas para sintetizar carbohidratos. Este proceso fotosintético representa un impacto de gran importancia para la sostenibilidad de la biodiversidad (Guerrero 1998, et al.).

Otra parte del dióxido de carbono reacciona con el agua formando ácido carbónico, el cual al disociarse en bicarbonato y carbonato, aporta las especies principalmente responsables de la alcalinidad o capacidad del agua para aceptar protones y para regular las variaciones significativas del $\mathrm{pH}$ del agua (acción buferante). Las especies carbonatadas, la acción de los microorganismos como catalizadores de las reacciones químicas acuáticas y otros parámetros físicos, químicos y microbiológicos, son factores determinantes de la calidad de los cuerpos de agua.

El resto del dióxido de carbono se acumula en la troposfera, capa atmosférica en contacto con la superficie terrestre, en donde junto con otros gases traza, como ozono, metano, óxido nitroso, tiene la función de regular la temperatura media de la tierra (Miller 1992).

Las excesivas emisiones de $\mathrm{CO}_{2}$ y otros gases alteran las concentraciones de los gases invernadero, con lo cual se impide la salida al espacio de la radiación infrarroja reemitida por la superficie terrestre, determinando un incremento de la temperatura global y dando así origen al efecto invernadero, de catastróficas consecuencias.

\section{ESTRATEGIA DIDÁCTICA INTERDISCIPLINAR INTEGRADA}

La estrategia didáctica con enfoque interdisciplinar, utiliza los nuevos enfoques y estructuras epistemológicas, históricas, filosóficas, pedagógicas y metodológicas con recursos que facilitan al profesor y a sus alumnos asumir una actitud crítica, reflexiva y de compromiso para emprender acciones educativas que coadyuven en la reducción y manejo de las situaciones ambientales riesgosas.

El enfoque interdisciplinar implica que se debe ubicar el objeto de trabajo o problema, con los conceptos y experiencias de las demás disciplinas, para que desde éstas se puedan aportar estrategias de solución a los problemas identificados.

\section{ENFOQUE INTERDISCIPLINAR Y CONCEPTOS INTEGRADORES}

Toda forma de interacción antrópicanatural representa una alteración con impactos positivos o negativos en el ambiente, parlo tanto para comprender mejor el impacto generado por las emisiones de $\mathrm{CO}_{2}$, éste puede representarse por un concepto clave o estructura de conocimiento, el cual se relaciona con conceptos afines o estructuras de conocimiento referidas a diversos factores ambientales. Cualquier alteración generada por el concepto clave o problema, no estará aislada de las demás estructuras de conocimiento, sino que las afectara en su contexto particular y global. Para articular el concepto clave con los conceptos hidrosfera, atmósfera, litosfera, biodiversidad, energía y otros, y con las actividades del aula, se puede utilizar los conceptos integradores (Guerrero 1994), los cuales desempeñan el papel de ejes articuladores del conocimiento 
(García 1992) y alrededor de éstos es posible interrelacionar y construir conceptos de una disciplina en interacción con conceptos de otras áreas o factores ambientales (mapa conceptual). El mapa conceptual permite tener una visión sistémica de las diversas estructuras de conocimiento que intervienen en el proceso de enseñanza desde la perspectiva del profesor y en el proceso de aprendizaje tanto del profesor como de los estudiantes.

\section{DIAGRAMA CONCEPTUAL QUE ARTICULA LOS CONCEPTOS Y EXPERIENCIAS DE LAS DISCIPLINAS CON EL IMPACTO AMBIENTAL GENERADO POR LAS EMISIONES DE $\mathrm{CO}_{2}$}

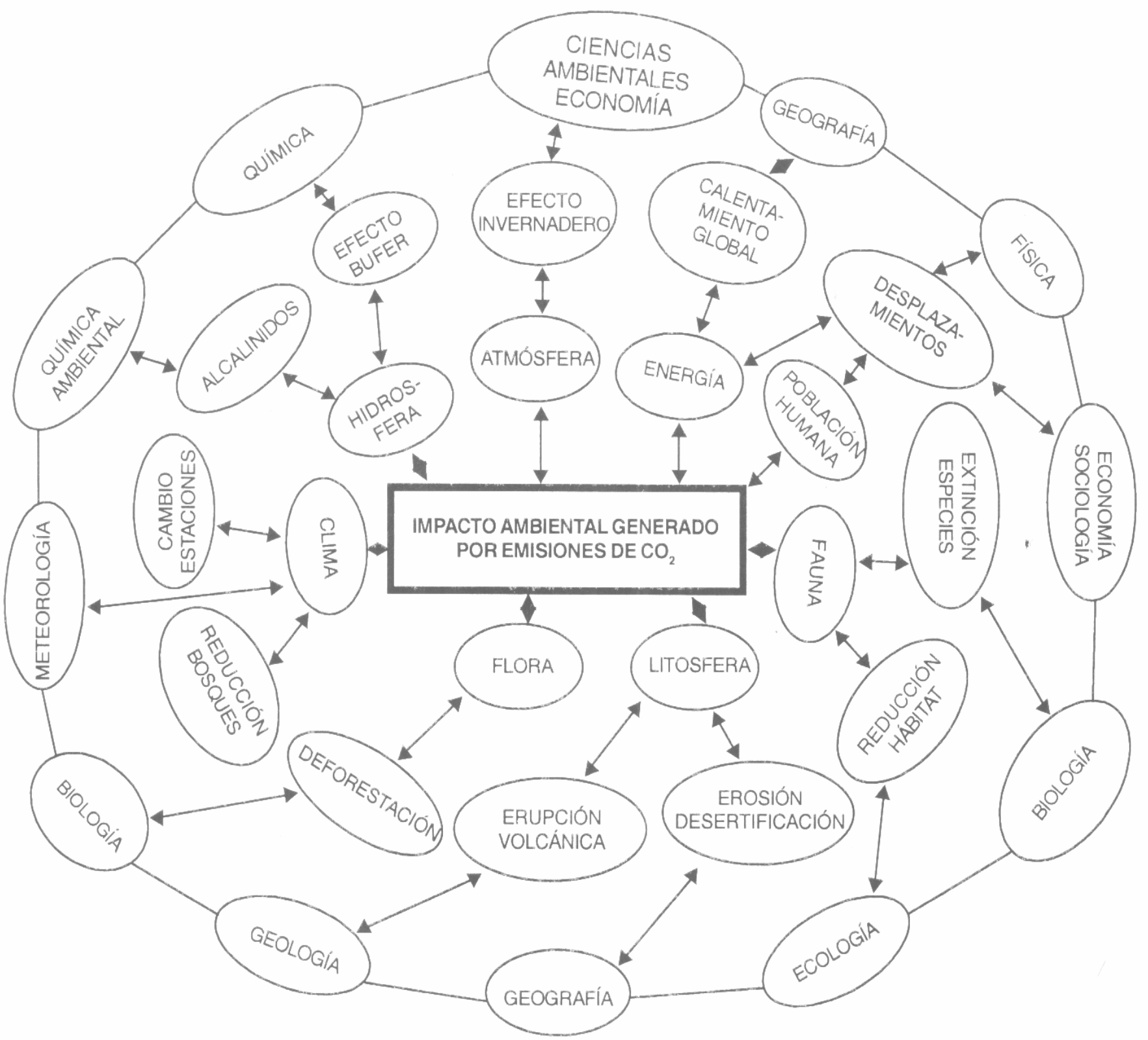




\section{MAPA CONCEPTUAL SOBRE IMPACTO AMBIENTAL POR EMISIONES DE $\mathrm{CO}_{2}$.}

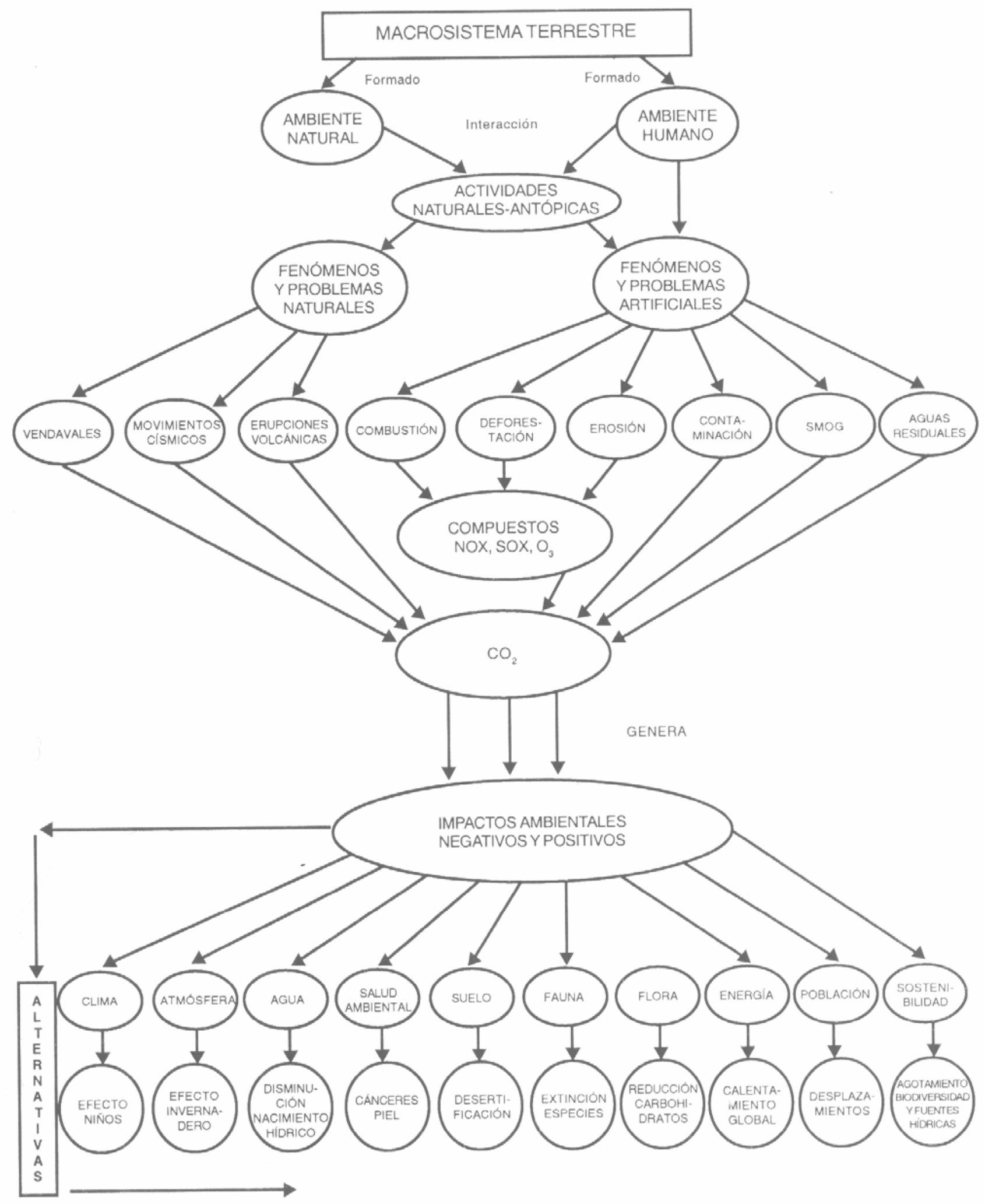




\title{
IMPACTO AMBIENTAL PRODUCIDO POR LAS EMISIONES DE $\mathrm{CO}_{2}$
}

\author{
INTERACCIÓN DIOXIDO DE CARBONO-GASES TRAZA EN LA TROPOSFERA
}

El contenido troposférico normal de $\mathrm{CO}_{2}$ es solo $0.0314 \%$ en volumen, el cual ha sido tremendamente excedido por las emisiones antropogénicas. La combustión de combustibles fósiles (petróleo, hullas, gas natural) genera cerca del $67 \%$ de $\mathrm{CO}_{2}$ presente en el ambiente y la deforestación produce cerca del 33\% (Miller 1994). Los países desarrollados, que usan grandes cantidades de dichos combustibles causan las mayores alteraciones ambientales, por las emisiones de $\mathrm{CO}_{2} ., \mathrm{SO}_{2}, \mathrm{NO}_{x}, \mathrm{O}_{3}, \mathrm{y} \mathrm{CH}_{4}$. El contenido de agua en la atmósfera varía del 1-3\% en volumen, el 96\% restante de la atmósfera terrestre consiste de nitrógeno $(78.08 \%)$, oxígeno $(29.95 \%)$ y argón $(0.934 \%)$ componentes mayores, luego el contenido de los gases traza solo representa pequeñas cantidades $\left(\mathrm{CH}_{4}, \mathrm{CO}_{2}, \mathrm{CO}, \mathrm{N}_{2} \mathrm{O}, \mathrm{HNO}_{3}, \mathrm{SO}_{2}, \mathrm{NH}_{3}, \mathrm{H}_{2}, \mathrm{H}_{2} \mathrm{O}_{2}, \mathrm{HO}, \mathrm{HO}_{2}, \mathrm{CS}_{2}, \mathrm{CCl}_{2} \mathrm{~F}_{2}\right.$, $\mathrm{H}_{3} \mathrm{CCCl}_{3}$, entre $1 \times 10^{-3}-1.6 \times 10^{-7}$ ) (Manahan, 1994). Las actividades humanas $\mathrm{O}$ antropogénicas no alteran ni modifican significativamente las concentraciones de los componentes mayores, pero si la concentración de los gases traza, lo cual ocasiona graves problemas ambientales.

El efecto invernadero normal o "forzamiento radiactivo", resulta de la habilidad de la atmósfera para transmitir radiación visible y ultravioleta que son absorbidas y devueltas por la superficie terrestre en forma de radiación infrarroja, la cual es atrapada por los gases invernadero $\left(\mathrm{CO}_{2}, \mathrm{CH}_{4}, \mathrm{~N}_{2} \mathrm{O}, \mathrm{O}_{3}, \mathrm{CEC}\right)$ sin lo cual la tierra estaría por debajo de $0^{\circ} \mathrm{C}$ y el agua permanecería en forma de hielo.

Los componentes mayores de la atmósfera (troposfera) $\mathrm{N}_{2}, \mathrm{O}_{2}$. y $\mathrm{Ar}$, son infrarrojamente inactivos. El vapor de agua, especie dominante en la troposfera absorbe el $80 \%$ de la radiación infrarroja emitida por la tierra, esto explica porque el enfriamiento nocturno es tan rápido en climas secos (desiertos y Antártida) (Trogler 1995). Junto al agua, están los gases invernadero, que también absorben radiación infrarroja y lo cual contribuye al $55 \%$ del "forzamiento radiactivo" o efecto invernadero causado por las emisiones provenientes de actividades humanas a la atmósfera, lo cual ha generado un incremento en la temperatura global (artificial) impacto ambiental negativo del $\mathrm{CO}_{2}$, con graves consecuencias ambientales.

Se ha estimado que la combustión de combustibles fósiles y no fósiles, está aportando $\mathrm{CO}_{2}$ a la atmósfera, y generando cerca del 50\% del calentamiento global (Kaufman 1996). El cultivo de arroz, ganadería y producción de aceites originan $\mathrm{CH}_{4}$ y aportan un $15 \%$ del total de contaminantes; el uso de fertilizantes, la deforestación y la síntesis de ácidos, aportan $6 \%$ de $\mathrm{N}_{2} \mathrm{O}$, la industria de plásticos y el uso de aerosoles producen clorofluorocarbonos (CFC) y aportan 11\%, la refrigeración produce $\mathrm{CFC}, \mathrm{O}_{3}$ y gases invernadero y aporta el 10\%. (Trogler 1995).

\section{INTERACCIÓN-DIÓXIDO DE CARBONO-ALCALINIDAD DEL AGUA}


El Dióxido de carbono y las especies carbonatadas ejercen una poderosa influencia en la química del agua y en buena parte de su aptitud de uso para diferentes propósitos. En el medio acuático existe una correlación muy interesante entre el oxígeno disuelto producido por los vegetales para abastecer los requerimientos respiratorios de peces y el $\mathrm{CO}_{2}$. producido por estos para ser absorbido por las especies vegetales en la fotosíntesis.

Los gases $\mathrm{O}_{2}, \mathrm{~N}_{2}, \mathrm{CH}_{4}, \mathrm{NO}, \mathrm{H}_{2}$, se encuentran disueltos en el agua y no generan ninguna reacción. Su solubilidad se puede determinar mediante la Ley de Henry (Manahan 1994). $\mathrm{El} \mathrm{CO} 2$ por el contrario, si reacciona con el $\mathrm{H}_{2} \mathrm{O}$ de acuerdo con las siguientes reacciones:

$$
\begin{aligned}
& \mathrm{CO}_{2(\mathrm{~g})}+\mathrm{H}_{2} \mathrm{O}_{(\mathrm{l})} \rightleftarrows \mathrm{H}_{2} \mathrm{CO}_{3}(\mathrm{AC}) \quad \text { o también } \\
& \mathrm{CO}_{2(\mathrm{~g})}+\mathrm{H}_{2} \mathrm{O}_{(\mathrm{l})} \rightleftarrows \mathrm{H}_{(\mathrm{ac})}^{+}+\mathrm{HCO}_{3} \quad \text { primer proceso de disociación } \\
& \mathrm{HCO}_{3} \text { (ac), } \longleftrightarrow \mathrm{H}_{(\mathrm{ac})}^{+}+\mathrm{CO}_{3} \quad \text { segundo proceso de disociación }
\end{aligned}
$$

Con los valores de $\mathrm{K}_{1}$ y $\mathrm{K}_{2}$ para el primer y segundo proceso de disociación, se pueden calcular jas fracciones (a) de $\mathrm{CO}_{2}, \mathrm{HCO}_{3}-$ y $\mathrm{CO}_{3}{ }^{\prime}$. Sustituyendo en las expresiones de las fracciones, las expresiones de $\mathrm{K} 1$ y $\mathrm{K} 2$ se obtienen las ecuaciones para calcular las fracciones de $\mathrm{CO}_{2}, \mathrm{HCO}_{3}{ }^{-}$, y $\mathrm{CO}_{3}{ }{ }^{2}$, con los valores de $\mathrm{pH}$ desde 1 hasta 14.

La representación gráfica de los valores de estas fracciones obtenidas en función de los valores de $\mathrm{pH}$ registrados para las aguas naturales, ofrece una indicación precisa sobre cual de las especies mencionadas es la que más contribuye al valor de $\mathrm{pH}$ en ese cuerpo de agua.

La alcalinidad de un cuerpo de agua se refiere a su capacidad para aceptar protones. El carbonato, el bicarbonato y los iones hidroxilo presentes en el agua, son los responsables de aceptar los protones. El carbonato, al aceptar protones, produce bicarbonato y luego el bicarbonato al aceptar protones se convierte en ácido carbónico el cual se disocia en 002 y agua en un sistema de equilibrio reversible. Este proceso de interconversión de unas especies en otras permite amortiguar variaciones significativas de $\mathrm{pH}$, cumpliendo así la acción buferante de los cuerpos de agua. En un proceso de valoraión con ácido para calcular la alcalinidad total, utilizando fenoftaleina para el primer punto de equivalencia, y naranja de metilo para el segundo, los virajes de color de la solución representan la capacidad del agua para aceptar protones, es decir la conversión del carbonato a bicarbonato y de éste a ácido carbónico y a $\mathrm{CO}_{2}$.

\section{INTERACCIÓN -DIÓXIDO DE CARBONO- CON FLORA Y FAUNA}

Más de tres cuartas partes del metano que ingresa a la atmósfera proviene de la descomposición de la biomasa o materia orgánica en la forma de residuos. La producción de biogás (metano y dióxido de carbono) a partir de estiércol de animales y residuos vegetales (aves, porcinos, ovinos, bovinos, equinos, residuos orgánicos, pulpa de café, corteza de árboles, bagazos, paja, semillas, hortalizas, frutas, cascarilla de arroz) 
mediante procesos de digestión anaeróbica es fuente viable de energía renovable y una solución a los problemas de disposición de residuos, deforestación, agotamiento de nacimientos hídricos, extinción de especies y control de cambios climáticos, por cuanto se detendría la tala de bosques para leña y se reduciría el uso de hulla y derivados del petróleo.

El proceso se fundamenta en la producción de biomasa mediante síntesis de clorofila a partir de gas carbónico y bicarbonato en el suelo y en el agua, la posterior oxidación de la biomasa a $\mathrm{CO}_{2}$ y la reducción de $\mathrm{CO}_{2}$ a $\mathrm{CH}_{4}$ así:

$\begin{array}{ll}\mathrm{CO}_{2}(\mathrm{~g})+\mathrm{H}_{2} \mathrm{O}_{(\mathrm{l})}+\mathrm{hn} \text { (fotones) } & \left(\mathrm{CH}_{2} \mathrm{O}\right)_{\text {(biomasa) }}+\mathrm{O}_{2} \\ \mathrm{HCO}_{3} \text { (ac) }+\mathrm{HO}_{2}+\mathrm{hn} \text { (fotones) } & \left(\mathrm{CH}_{2} \mathrm{O}\right)_{\text {(biomasa) }}+\mathrm{OH}+\mathrm{O}_{2}\end{array}$

Esta biomasa es la clave para sustentar la vida de diversas especies animales y para producir energía renovable de bajo costo y bioabono por digestión anaeróbica:

$\begin{array}{lll}1 / 4\left(\mathrm{CH}_{2} \mathrm{O}\right)+1 / 4 \mathrm{H}_{2} \mathrm{O} & \stackrel{\text { bacterias }}{\longrightarrow} & 1 / 4 \mathrm{CO}_{2}+\mathrm{H}^{+}+\mathrm{e}^{-} \quad \text { (reacción de oxidación) } \\ 1 / 8 \mathrm{CO}_{2}+\mathrm{H}^{+}+\mathrm{e}^{-} & \stackrel{\text { bacterias }}{\longrightarrow} & \left.1 / 8 \mathrm{CH}_{4}+1 / 4 \mathrm{H}_{2} \mathrm{O} \text { (reacción de reducción del } \mathrm{CO}_{2}\right) \\ \text { Sumatoria: } 1 / 4\left(\mathrm{CH}_{2} \mathrm{O}\right) & \stackrel{\text { bacterias }}{\longrightarrow} & 1 / 8 \mathrm{CH}_{4}+1 / 8 \mathrm{CO}_{2} \text { (Manahan 1994) }\end{array}$

La reducción de $\mathrm{CO}_{2}$ a $\mathrm{CH}_{4}$ por este proceso, representa un impacto ambiental positivo muy importante para producir energía renovable limpia y de bajo costo con grandes repercusiones en la disminución de la contaminación por residuos y en la mejora de la calidad ambiental total. Teniendo en cuenta el proceso anterior de reducción de dióxido de carbono a metano, es trascendente preguntar si se pueden disponer de tecnologías modernas, alternativas y limpias que puedan reconvertir las grandes cantidades de $\mathrm{CO}_{2}$ emitido por actividades humanas a metano, combustible renovable y de poco costo.

Por otra parte, la disminución del $\mathrm{CO}_{2}$ corporal en aves durante periodos climáticos demasiado cálidos afecta negativamente su proceso de reproducción.

Las reacciones:

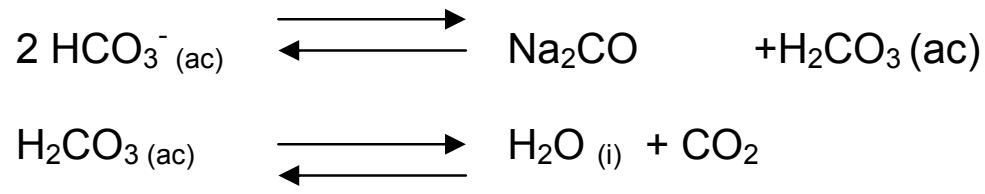

Permiten explicar, porque las cáscaras de huevo de las gallinas son demasiado delgadas y frágiles en climas cálidos. Por carecer de glándulas sudoríparas, las gallinas deben jadear como los perros para remover el calor del cuerpo. La remoción del calor va acompañada de un incremento en el $\mathrm{CO}_{2}$ exhalado lo cual lleva a una disminución del mismo en el cuerpo del animal. La disminución de $\mathrm{CO}_{2}$ hace que los sistemas de equilibrio de los siguientes procesos: 


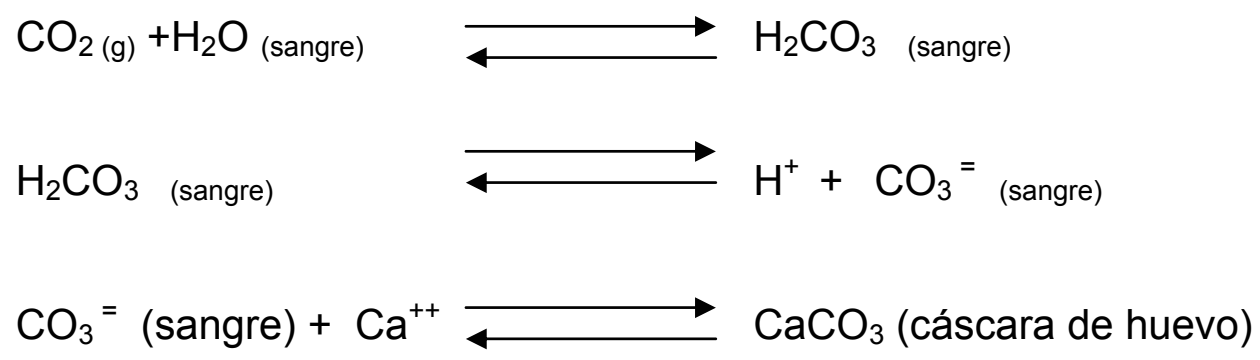

Se desplacen hacia la izquierda para reponer el $\mathrm{CO}_{2}$ perdido, desfavoreciendo la concentración de carbonato de calcio requerido para la formación de la cáscara de huevo, obteniéndose cáscaras más frágiles y más delgadas. Para procurar una alternativa de solución al problema, se debe suministrar a las aves agua carbonatada para beber, la cual ayuda a compensar el $\mathrm{CO}_{2}$ perdido y a darle consistencia a las cáscaras de huevo (De Lorenzo 2001).

\section{INTERACCIÓN -DIÓXIDO DE CARBONO CON ELSUELO Y EL AGUA}

El dióxido de carbono desempeña una función articuladora en la secuencia de reacciones del ciclo del carbono, en especial las reacciones reversibles de formación y disociación del ácido carbónico, bicarbonato de sodio, ion carbonato y carbonato de calcio. La secuencia anterior de reacciones contribuye a que el horizonte superficial del suelo presente características acídicas y los horizontes más internos propiedades básicas. Se destaca también la contribución de las especias carbonatadas a la formación de sedimentos y material rocoso de los cuales hace parte el carbonato de calcio (Singer 1999).

Las erupciones volcánicas provenientes del fondo de cuerpos de agua ubicados en capas estratificadas sin mucha mezcla, emiten $\mathrm{CO}_{2}$, lo cual puede constituirse en un gran riesgo ambiental, debido a las altas presiones que se pueden producir por las emisiones de gas carbónico en esos cuerpos dé agua. El equilibrio de la reacción se puede desplazar hacia la izquierda (De Lorenzo 2001).

$$
2 \mathrm{NaHCO}_{3} \rightleftarrows \mathrm{Na}_{2} \mathrm{CO}_{3(\mathrm{ac})}+\mathrm{H}_{2} \mathrm{CO}_{3} \rightleftarrows \mathrm{H}_{2} \mathrm{O} \sim+\mathrm{CO}_{2}(\mathrm{~g})
$$

En razón de la ocurrencia de fenómenos naturales como actividades volcánicas, vendavales o movimientos sísmicos las aguas ubicadas en las capas estratificadas, son interrumpidas haciendo que la capa de la base se agite y se proyecte hacia la superficie, donde la reducida presión permite la salida del gasa carbónico a la atmósfera con mucha fuerza alcanzando muchos metros de altura y causando daños a la vegetación en sus alrededores. Puesto que la densidad del $\mathrm{CO}_{2}$ es mayor que la del aire respirable desprovee a los individuos del oxígeno y los expone a morir por sofocación debida a la inhalación de $\mathrm{CO}_{2}$. Se han reportado casos hasta de 1.800 personas muertas en sitios como algunos lagos donde persiste la actividad volcánica (De Lorenzo 2001).

En conclusión se propone abordar la enseñanza de las ciencias experimentales mediante el enfoque didáctico interdisciplinar, articulado con los conceptos integradores, en los cuales los problemas ambientales se ubican como conceptos clave estudiados desde la perspectiva de cualquier disciplina, mediante las distintas acciones o estrategias 
metodológicas, buscando aportar soluciones locales, regionales, nacionales e internacionales, a los problemas originados parlas relaciones antrópico - naturales.

\section{ALTERNATIVAS EDUCATIVAS, TECNOLÓGICAS Y LEGALES PARA REDUCIR LOS IMPACTOS AMBIENTALES OCASIONADOS POR EMISIONES DE $\mathrm{CO}_{2}$}

\section{ALTERNATIVAS EDUCATIVAS}

El proceso de trabajo escolar en interacción con el ambiente natural y social ayuda al estudiante a internalizar formas de pensamiento filosófico, epistemológico, científico, cultural y político acerca de lo que representa el ambiente total en el contexto de la sostenibilidad.

La interpretación, argumentación y propuestas educativas alrededor del impacto ambiental generado por emisiones de $\mathrm{CO}_{2}$ están conectadas con la perspectiva compleja del ambiente y contribuyen con nuevas aproximaciones al análisis de los núcleos temáticos disciplinares, a la relevancia del uso de las concepciones de los alumnos al desarrollo de la capacidad mental para comprender las interrelaciones de los sistemas de ideas de las ciencias con el sistema de ideas de la cotidianidad.

La interacción de las actividades ambientales con las actividades del aula, deben generar un profundo cambio de nuestro comportamiento consumista y destructivo por una cultura del uso racional y recuperativo de los recursos naturales en el contexto de las sociedades del presente y del futuro.

\section{ALTERNATIVAS TECNOLÓGICAS}

Los instrumentos aportados por las tecnologías modernas deben permitir utilizar nuevos recursos y menos energía y contribuir a mejorar la calidad ambiental.

Se requiere de tecnologías que permitan utilizar más energía solar. Las industrias ensambladoras deben diseñar motores que utilicen menos combustibles fósiles, con alternativas de uso de electricidad, gas y celdas de hidrógeno.

- Implementar en las grandes ciudades el uso de la bicicleta y los sistemas de transporte masivo.

- Apoyar el desarrollo y utilización de "Tecnologías alternativas para la producción de Energía Renovable, usando estiércol de animales y residuos orgánicos mediante procesos químicos anaeróbicos "(Guerreo Jaime. XXIV Congreso Latinoamericano de Química - Lima - Perú. 2000).

\section{ALTERNATIVAS LEGALES}


Establecer Legislación Internacional para actualizar industrias con tecnologías eficientes y no contaminadoras que no dependan de combustibles fósiles.

- Establecer legalmente el servicio social ambiental para los ciudadanos que culminen estudios medios y universitarios.

- Buscar por todos los medios legales que los países reduzcan las emisiones de $\mathrm{CO}_{2}$, acogiéndose a combustibles alternativos y a los protocolos internacionales.

- Establecer una política de forestación Internacional a corto, mediano y largo plazo en el planeta.

\section{BIBLIOGRAFÍA}

1. García, J. E. et al. Investigando Nuestro Mundo. 1992, p. 40.

2. Guerrero S., Jaime E. Ambientalización del Currículo Mediante la Construcción Significativa de Conceptos integradores. Enfoques Pedagógicos. Volumen 2. No. 1.1994, p. 44.

3. Guerrero S. Jaime E. et al. Los impactos Ambientales producidos por la Combustión del Propano sobre el planeta GAIA, desde una estrategia pedagógica multidisciplinar integrada. Revista U.D.C.A. 1998, pp. 21, 22.

4. Delorenzo, Ron. From Chicken Breath to the killer lakes of Cameroon: Uniting Seven Interesting phenomena with a Single Chemical underpinning. Journal of Chemical Education. Volume 78 No. 2-2001, pp. 191-192.

5. Kaufman Don; Franz, Cecilia. Biosphere 2000. Second Edition. Kendall publishing company. 1996, p. 259

6. Manahan, Stanley. Environmental Chemistry. Sixth Edition. Lewis publishers. 1994, p. 259.

7. Miller Tyler. Ecologia y Medio Ambiente. Seventh Edition. Editorial Iberoamerica 199, p. 313.

8. Singer, Michael; Munns, Donald. Soils. Fourth Edition. Library Congress Catalegue. 1999, p. 208.

9. Trogler, William. The Environmental Chemistry of Trace Atmospheric Gases. Journal of Chemical Education. Volume 72. No. 11-1995, pp. 974-976. 